\title{
Pull and Push Elements of Entrepreneurship in South Africa: A Small- Scale Mining Perspective
}

Mkubukeli $Z^{*}$ and Cronje JC

Faculty of Informatics and Design, Cape Peninsula University of Technology, Cape Town, South Africa

\begin{abstract}
It is believes that small scale mining entrepreneurs are pushed into entrepreneurship by poverty, culture and their values. However, argue that small scale mining entrepreneurs are pulled into entrepreneurship because of their need to diversify and to generate income. This article gives a critical review of the research that was done to explore whether small-scale mining entrepreneurs are affected more by push factors or by pull factors or whether both play a strong role. This comprised a literature review. In this paper, we highlight the findings of the systematic literature review on the push and pull elements of entrepreneurship in South Africa. It is not clear as to whether push factors or pull factors predominate or whether these key factors influence entrepreneurs equally. What emerged is that people are driven by different motives. These motives are influenced by factors such as age and gender.
\end{abstract}

Keywords: Entrepreneurship; Research; Gender; Economies; Financial rewards

\section{Introduction and Background}

The Push and Pull Factor theory of entrepreneurship takes the view that there are two main reasons that make people decide to become entrepreneurs [1-5]. The theory suggests that some people are forced into entrepreneurship by their circumstances, while others are enticed or drawn into entrepreneurship because of their expertise and skills or an opportunity that presents itself. Typically, low-ability entrants to self-employment are pushed into entrepreneurship. In other words, they are forced into entrepreneurship by adverse circumstances. In contrast, others are lured or attracted into entrepreneurship by an opportunity that presents itself.

The research problem underpinning this study is that it is not clear whether small-scale mining entrepreneurs are pulled or pushed into entrepreneurship or whether it is more accurate to say that a combination of these factors influences the decision to become smallscale mining entrepreneurs.

In order to explore this problem, a review of the relevant literature was first undertaken. This article explores the findings of the literature research.

In South Africa large, established mining companies are favoured, and small-scale mining enterprises are marginalised. It seems that individuals in small-scale mining are either forced to become entrepreneurs because of the circumstances they find themselves in or they are enticed into entrepreneurship because of the skills they have or the opportunities that arise [5]. Although there are various studies on what informs people's decisions to become entrepreneurs, there have been very few attempts to gain in-depth information on the push and pull factors of entrepreneurship in the case of small-scale miners. The findings thus far are far from definitive. In their study, Evan and Dean [6] argue that people are often pulled into entrepreneurship by their need for financial freedom and independence. Shane et al. [7] reaches a similar conclusion as do Barringer and Ireland [8]. Shane et al. [7] also note the reasons that might push people to become entrepreneurs. They mentioned that one of many reasons that force people to become entrepreneurs is that they are jobless or that they find the jobs they have are unpalatable. Kirkwood [9] concurs that people are pushed into entrepreneurship by their difficult circumstances.
In his article on the role of small-scale mining in Sub-Saharan Africa, Hilson [2] takes an unusual approach to small-scale mining poverty and development in Sub-Saharan Africa, which is usually viewed as a minor contributor to the economy. In his view, smallscale mining (SSM) is extremely important to the economies of rural communities since over two million people are employed in SSM. In addition to this, he noted the dialogue on small-scale mining does not reflect the current reality. The literature seems to see the reasons for small-scale mining in simple terms of being poverty driven or wealth orientated. Like Hilson [1-3], take a more complex view. They contend that people engage in small-scale mining because they want to diversify their income and have new opportunities, not because they are poverty stricken. Pegg [4] also questions the view that people decide to become small scale miners because they wish to alleviate their poverty, claiming that small-scale mining does not necessarily reduce poverty; indeed it can perpetuate it.

The lack of clarity on whether small-scale mining entrepreneurs are pushed rather than pulled into entrepreneurship or vice versa clearly indicated a need for exploratory research of the key factors. A systematic review was therefore undertaken.

The first step in generating data for this literature was the identification of exclusion and inclusion criteria to be used to select articles. A decision was taken to download articles on the topic published between 1980 and 2017 so that sufficient data would be generated to identify patterns in SSM. An initial survey of literature showed a spark in the 1980. EBSCO host Academic Search Premier, Elsevier SD Freedom Collection, EBSCO host Business Source Premier, Emerald insight, and Pro Quest Social Science was the databases used. More than 100 scholarly articles were identified. These articles were analysed

${ }^{*}$ Corresponding author: Mkubukeli Z, Faculty of Informatics and Design, Cape Peninsula University of Technology, Symphony Way, Bellville, Cape Town, South Africa, Tel: +27624424606; E-mail: zmkubza@gmail.com

Recieved November 02, 2018; Accepted November 23, 2018; Published November 30, 2018

Citation: Mkubukeli Z, Cronje JC (2018) Pull and Push Elements of Entrepreneurship in South Africa: A Small-Scale Mining Perspective. J Entrepren Organiz Manag 7: 252. doi: 10.4172/2169-026X.1000252

Copyright: (c) 2018 Mkubukeli Z, et al. This is an open-access article distributed under the terms of the Creative Commons Attribution License, which permits unrestricted use, distribution, and reproduction in any medium, provided the original author and source are credited. 
so that only those that specifically dealt with push and/or pull factors could be selected. A list of the articles that were selected is tabulated below under the heading recent studies on small scale mining. The next section describes the theoretical foundation underpinning this study, before contextualising small scale mining and entrepreneurship.

\section{Recent Studies on Small-Scale Mining}

The following table presents the relevant studies conducted on small-scale mining between 1980 and 2017. The table lists the author, year of the research, the title of the study, focus area and the key words used in order to search the literature (Table 1).

\section{Theoretical Underpinning}

This paper used the push and pull factor theory of entrepreneurship [5] as a lens through which to view the research problem. This theory suggests that some people are forced into entrepreneurship by their circumstance, while others are enticed into entrepreneurship because of their skills or an opportunity that presents itself.

\section{Push and Pull Elements of Entrepreneurship: A Small- Scale Mining Perspective?}

Africa has a rich endowment of mineral resources. These mineral play an essential role in the African economy as various businesses depend on mining to be successful. For example, mining companies in the Democratic Republic of Congo (DRC) substantially contribute to the global production of tin, tantalum, diamonds, cobalt and tines. For example, the DRC was responsible for over $50 \%$ of the global production of cobalt in 2009. Another example is Angola which has an abundance of oil reserves and produces more than two million barrels daily. It is closely followed by Nigeria. Botswana, where the economy initially gained immensely from the discovery of precious stones, the situation is different. According to the Botswana government has a long way to go to effectively managing its mineral wealth and deriving the full economic and social benefit from it.

In countries such as Mozambique and South Africa, despite being rich in minerals, the vast majority of previously disadvantaged citizen have not benefited from the exploitation of minerals. It is demonstrated that the South African platinum sector was dominated by a few industrialists, with little benefit being passed on to previously disadvantaged citizens of the country. There are a very few successful business start-ups in the mining sector, particularly in the small scale mining sector. Small-scale miners have a number of obstacles to overcome. It is difficult to raise the funds needed to purchase operating licences and the cost of prospecting. Although mining in Africa has a critical role to play in the economy, the majority of its people have not yet directly benefitted from it.

The question as to whether small-scale miners are pushed and/or pulled into small-scale mining is directly related to the current level of bureaucracy and the initial capital needed to operate a mine. In answering this question, we draw on the findings of various scholars. To deal with the negative legacies of the past, the newly elected government established an empowerment strategy to overcome the injustices of the past pertaining to the mining industry. The envisioned strategy was the Broad-Based Black Economic Empowerment Act 53 of 2003. The aim of the act was to ensure that indigenous people would get equitable access to the mining industry. This was aimed at ensuring more black participation in sectors long dominated by the white population, not only in mining but in other industries. Despite this initiative, very few previously disadvantaged citizens have been pulled into small scale mining entrepreneurship [10]. In the following figure, we use the push and pull theory as a lens through which to view the major factors that influence decisions to become entrepreneurs (Figure 1).

\section{Push elements of entrepreneurship}

In this section, we discuss the elements that force people to become business owners. These are job insecurity, unemployment, disagreement with management, and the inability to fit in with the organisation. Having no other way of generating an income was also identified as a major push element. Shane et al. [7] and Kirkwood [9] consider job dissatisfaction and other negative job-related circumstances as significant push element.

Men and women become entrepreneurs for different reasons. In his study, Kirkwood [9] explored the motivational factors in the push and pull factor theory from a gender perspective. His study found that women were driven into entrepreneurship by the needs of their children and a desire for independence, while men were pulled into starting their own business mainly because of job dissatisfaction. A more complex view seems necessary. Usefully argue that the major pull elements of entrepreneurship for women are lower salaries, insufficient family income and an inability to find employment. Van Straaten [11], Hentschel et al. [12], Kirkwood [9], Veiga et al. [13], Werthmann [14], Hilson [2], Sousa et al. [15] and Hilson, [16] note that a large number of small-scale miners are forced into becoming entrepreneurs by poverty and unemployment. Hilson [1-3] argues that culture and values also play a strong role. Pegg [4] argue that small-scale miners are pulled into entrepreneurship by their need to generate wealth and to be independent. The range of views heightens the need for a study to explore whether small-scale miners are pushed and/or pulled into entrepreneurship. In what follows, more detailed attention is given to some of the factors that push people into entrepreneurship.

\begin{tabular}{|l|l|l|}
\hline Title of the Study & Area & Keywords \\
\hline $\begin{array}{l}\text { Achievement, power and managerial motivation: selecting } \\
\text { managerial talent with job choice exercise }\end{array}$ & Pull elements of entrepreneurship \\
\hline Self-employment entry across industry groups & Motivating factors for start-ups \\
\hline $\begin{array}{l}\text { Entrepreneurship. A south African perspective } \\
\text { Opportunity and/or necessity entrepreneurship? The impact of } \\
\text { the socio-economic characteristics of entrepreneurs }\end{array}$ & Entrepreneurship & Push and pull elements of entrepreneurship \\
\hline $\begin{array}{l}\text { Farmer's motives for diversifying their farm business- the } \\
\text { influence of family }\end{array}$ & Motives of diversifying & Pull elements \\
\hline $\begin{array}{l}\text { Factors motivating young south African women to become } \\
\text { entrepreneurs }\end{array}$ & Motivating factors & Push and pull factor theory \\
\hline Challenges and prospects of small-scale mining & Challenges in small scale mining \\
\hline Push versus pull entrepreneurship: An ambiguous distinction? & Push and pull elements of entrepreneurship \\
\hline
\end{tabular}

Table 1: An overview of the studies on pushes and pull elements of entrepreneurship and small-scale mining. 


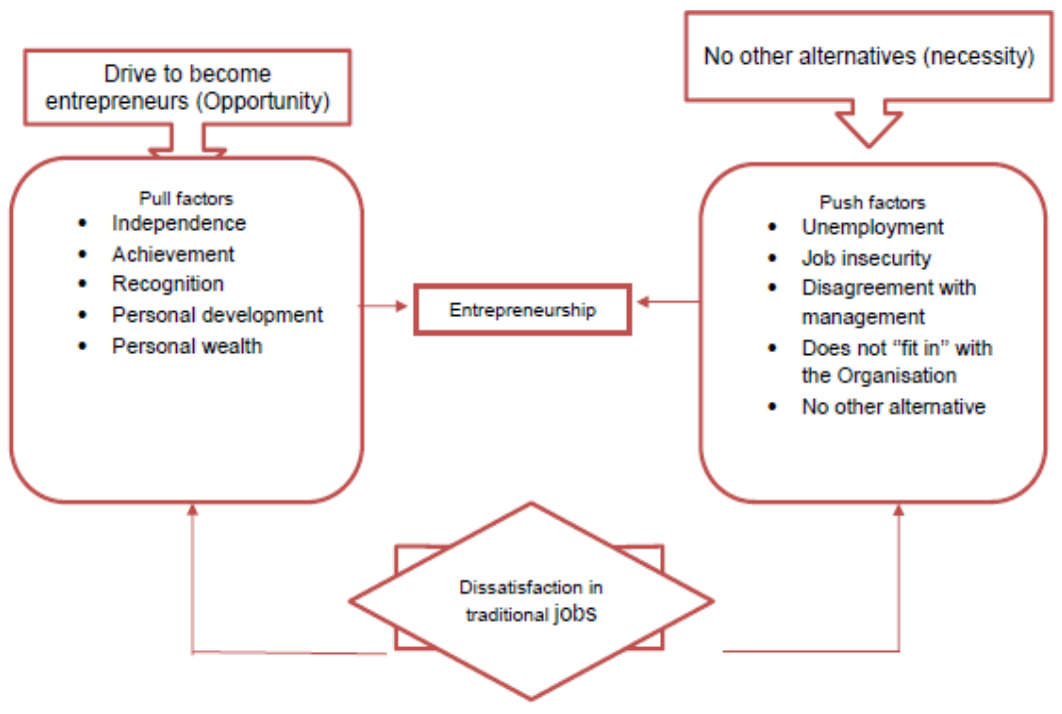

Figure 1: Push and pull factor theory of entrepreneurship.

Unemployment: He used Dubin's theory for their study on entrepreneurial opportunity identification and development. The study identified the entrepreneur's personality traits, social networks and prior knowledge as encouraging entrepreneurial alertness to business opportunities. Needless to say, unemployed people are looking for a means of making a living rather than business opportunities. Moreover, small scale mining is largely active in rural areas where a high percentage of people are unemployed [10]. Therefore, they are not lured into entrepreneurship by their personality skills and prior business knowledge. I would argue that small scale miners would not readily risk their lives by operating illegally in unsafe conditions underground where there are no proper health and safety procedures. It seems that, these small-scale miners operating a small-scale mine are doing so for only one reason only and that is because they have no other means of raising money [2,11-16]. It is fair to conclude that many individuals see entrepreneurship as a way of solving the problem of being unemployed.

A very small number of small-scale miners have experience of the mining industry as a result of having worked for large scale mining companies [16]. Although small-scale mining can be lucrative in rural communities, it remains a poverty driven initiative rather an entrepreneurially driven initiative. A study which cites the International Labour Organization established that more than 12 million people are either directly or indirectly employed by small-scale mining in Southern Africa alone. In similar vein, a study by Hilson [16] asserts that in small scale mining, entrepreneurs employ whoever is available in the host community, making it the leading employer in Southern African rural communities. In other business employees are recruited and interviewed, this is seldom the case in small-scale mining. As previously stated, small-scale miners generally employ anyone who is available. It is arrived at the interesting conclusion that women, especially uneducated women have greater prospects of employment in small-scale mining than in any other form of employment. It therefore reduces inequalities.

Hilson [16] suggest that there is a growing consensus that the workforce in small-scale mining is rapidly increasing because it is a poverty driven rather than entrepreneurially driven business.
Job insecurity: In most instances, employees who are employed on a contract basis face the uncertainty, of not knowing whether their contracts are going to be renewed or not. However, it is also true that employees become dissatisfied with the job they are doing [7]. Co et al. [17] state that job insecurities, lack of fulfilment in their jobs or retrenchment are valid reasons for deciding to become an entrepreneur. However, in his study Mkubukeli [10] noted that small-scale mining entrepreneurs do not seem to have started up their enterprises because they were affected by job insecurity. In addition, the reasons are more likely to be retrenchment, unemployment and employment that is seasonal only, as well as previous experience as a mine workers. It seems that a vast majority of people who start their businesses because of job insecurity are highly skilled people who branch into the same industry. Notwithstanding, there is no reason to believe that small- scale miners had job insecurity, rather faced retrenchment, simply because there are no set policies in small scale mining, they are hired and fired at any given time. That said, It should be noted that a person may be pushed into entrepreneurship by job insecurity and still be successful.

There is a dearth of published research on this particular element. This further strengthens the need for further exploration of this field.

Disagreement with management: On the one hand, low-ability entrants to self-employment are pushed entrepreneurs, in other words people forced into business by adverse circumstances. On the other hand, pulled entrepreneurs were lured into entrepreneurship by an opportunity that presented itself. Given the above, small-scale mining is predominately an informal activity with little or no expert task management. He describes task management as the process of organising a business into separate organisational functions. For instance, having a human department, marketing and public relations and so forth. Because there is no sense of the business as a whole, there is no management in the case of small-scale miners who mine independently and sell their raw material to Chinese middlemen, particularly in Ghana. However, in formal businesses, where the views of employees' conflict with those of management, the disagreements that result may sometimes lead employees to start their own business ventures. Mkubukeli [10] noted that In the case of small-scale mining entrepreneurs, this is not the case. 
A lack of recognition from employers may also cause discontent. For that reason, many employees choose to make self-employment a permanent solution (ibid.). At present, there is very little literature on small-scale mining and small-scale mining entrepreneurs and hardly any on their experience of being entrepreneurs. However, it does seem that small-scale mining entrepreneurs in Southern Africa employ whoever is available in the local community simply to reduce poverty [18]. This makes them the leading employer in Southern African rural communities [16]. Given that a vast majority of entrepreneurs were unemployed prior to engaging in small-scale mining, it is a fair assumption that few of those in small-scale mining were pushed into entrepreneurial enterprises because of a disagreement with management.

Does not "fit in" with the organisations: It is investigated that the development and cross cultural application of a specific instrument to measure entrepreneurial intentions. The study used the Ajzen's theory of planned behaviour to distinguish entrepreneurial intention. This research examined 519 individuals from Taiwan and Spain. The results suggested that cultural values modify how society perceives entrepreneurship. That said, in many parts of the world entrepreneurship is seen as culture and every business has its unique culture in terms of how business operations are run.

One of many reasons people leave their jobs to start a business is rooted in how things are done in the organisation that employs them or its ethos. Employees' views may often be at odds with that of the organisation. Co et al. [17] contend that people are sometimes pulled into entrepreneurship because of a lack of promotion opportunities or job satisfaction. In many such cases, they can use the experience they have gained to establish their own business. It is not yet clear, however, that small scale miners are pulled or pushed into small scale mining by disagreement with management.

A study by Venter et al. [19] looked at entrepreneurship from a developmental point of view and concluded that many entrepreneurs fail in business because they do not have a clear strategy or a background in business. Another study looked at women who left a position in an organisation to start their own business: self-reported motivations whether it correlates with success. To gather the data, they research surveyed 129 women executives and professional that had left large organisations. They found that women were pulled into entrepreneurship because their previous positions had not been sufficiently challenging. They were also pushed into entrepreneurship as a result of gender discrimination in large organisations.

Another study looked at deciding on an entrepreneurial career, testing the pull and push hypothesis. This study analysed whether the potential for increased life satisfaction pulls or job dissatisfaction pushes individuals towards an entrepreneurial career. A complicating factor is that what some may see as push elements, others see as push elements. This is one of the reasons for exploring these key factors.

No other alternatives: All over the world, small-scale mining employs a significant number of indigenous people in rural communities [12], thus playing a critical role in addressing unemployment and poverty in rural areas. In 2002, it was estimated that more than twelve million people globally were directly employed or involved in small-scale mining operations [12]. Hilson [2] contends that in subSaharan Africa, more than two million people were directly involved in small-scale mining operations. It seems that a relatively large number of African are employed in small-scale mining, albeit illegally or informally. As previously stated, small-scale mining entrepreneurs very often have no other alternative, given the scarcity of job in rural communities. Therefore, small-scale mining entrepreneurs may be said to be pushed into entrepreneurship because they have no other choice.

A study by Werthmann [14] investigated the concept of working in a boom town from a female perspective in the gold mining sector in Burkina Faso. This study revealed that, wherever there is small scale mining, drug abuse and prostitution is inevitable. This seems to be caused by market forces.

Small-scale mining is not without its difficulties. The Department of Water Affairs (2006:5) revealed that small-scale miners face several challenges such as lack of ownership, obtaining mining permits and human capital. This view is supported by the work of Hentschel et al. [12], Mutemeri and Petersen [20], Hentschel et al. [12], Mutemeri et al. [21]. Mutemeri et al. [21], conducted a study on small scale mining in South Africa in which they found that a vast majority of small scale miners run their businesses illegally or informally because they do not have permits. This situation is not limited to South Africa. Appiah [22] investigated the organisation of small-scale mining activities in Ghana. His research indicates that small-scale miners struggle to obtain licenses and to formalise their enterprise. This limits their access to technology and finance [23-25].

The literature concludes that the lack of an alternative source of income drives or pushes small scale miners into entrepreneurship. Appiah [22] explained that small-scale miners are ordinary citizens, often living in extreme poverty in informal settlements, with only one way to earn an income [26,27].

This section makes the case that small-scale miners are definitely pushed into entrepreneurship by their negative circumstances. It should be noted that the two major push elements are unemployment and the absence of another way of making money. The next section investigates to what extent small-scale miners can be said to be pulled into entrepreneurship $[28,29]$.

\section{Pull Factors to Entrepreneurship}

In this section, I discuss the elements that entice people into becoming entrepreneurs. In their study, Nieman and Nieuwenhuizen [5] assert that although some people are forced into entrepreneurship by their circumstances, others are attracted to it by their particular skills or by an opportunity that presents itself. Lending support to this premise is the work. They explored entrepreneurial motivation in an underdeveloped country: push and pull elements among MSEs in Uganda. This research found that push and pull elements are not mutually exclusive. There are several elements that entice people into becoming entrepreneurs. A few of these are listed below: independence, achievement, recognition, personal development and personal wealth [30]. According to the pull elements of entrepreneurship include but are not limited to: independence, self-fulfilment, entrepreneurial drive and desire for personal wealth. In their study, Shane et al. [7] suggest that the desire for independence and recognition is a major pull factor towards entrepreneurship, as is job dissatisfaction. It seems that people are also pulled into entrepreneurship by their need for independence or for financial rewards [6-8] support this view, saying that the vast majority of people are pulled into entrepreneurship by their desire to run their own business and the need for independence. However, there is no hard evidence on whether small-scale miners are pushed rather than pulled into entrepreneurship or vice versa, or whether they are pushed and pulled. This is a strong indication that further exploration in this regard is necessary [31]. 
As previously stated, van Straaten [11], Hentschel et al. [12], Veiga et al. [13], Werthmann [14], Hilson [2], Sousa et al. [15] and Hilson [16] argue that operating a small scale mine, as is the case with any other business, presents good prospects only if run effectively. However, if successful, these mines cannot only offer direct and indirect employment to miners and other industries, but they are also a vital part of the economy in rural communities. With this in mind, small-scale miners can be seen as both pushed and pulled into entrepreneurship simply because it can be seen as profit making business or as a way of making ends meet [32].

\section{Independence}

A study by Co et al. [17] asserts that people who establish their business are enticed into starting their businesses by the opportunities that are associated with independence. Shane et al. [7] argue a similar case, citing the fact that independence was ranked first as a pull factor into entrepreneurship across three different countries. He examines entry of women into self-employment and small business ownership. During their study, they interviewed 61 entrepreneurs and found that while many argue that women are pulled into entrepreneurship by their need for independence, flexibility and the hope of avoiding challenges in their employment, others argue that women are pushed into entrepreneurship by downsizing and restructuring in the private sector [33].

Barringer and Ireland [8] confirm that independence and the pursuit of financial rewards are the main reasons why people become entrepreneurs. On a different note, a study conducted demonstrates that desire to be in control is a strong factor in the decision to become an entrepreneur. It seems then that people are attracted to entrepreneurship by the prospect of being their own boss and the concomitant financial rewards, as well the prospect of gaining their independence [34]. However, this is rarely true of small-scale miners, according to Hilson [1-3]. Their main purpose is to obtain mineral resources and sell them in order to buy food for their families. Therefore, small-scale mining entrepreneurs cannot be said to be pulled into entrepreneurship. Hentschel et al. [12] present a telling argument that supports this view. They point out that unlike their large-scale mining counterparts, small scale mining entrepreneurs are poverty-alleviation orientated rather than commercially orientated.

\section{Achievement}

It conducted a longitudinal study of the cognitive factors that influence start up behaviour and successful venture creation. The aim of their study was to test the following hypothesis:

- H1: Potential entrepreneurs who offer internal and stable explanations for their plans for getting into business (e.g. "I have always wanted to own my own business") should be more likely to persist in actions that lead to successfully starting their business.

- H2: potential entrepreneurs with high personal efficacy scores should be more likely to persist in actions that lead to successfully starting a business.

He gathered data from 142 of the clients of a small business development centre. Of these, 30\% were female and $70 \%$ were men. One of the questions asked the participants to elaborate on their decision to become entrepreneurs. There was an $81 \%$ response to the question. The analysis of the answers revealed that:

HI (internal/stable attributions, e.g. "I have always wanted to be my own boss") was supported for female potential entrepreneurs, whereas external/stable attributions (e.g., "I had identified a market need") were significant for male potential entrepreneurs. SIC code classifications revealed no significant differences in the sorts of businesses being contemplated by women and men. $\mathrm{H} 2$ (personal efficacy) was not supported.

Many aspiring entrepreneurs are driven by the need for achievement. Managing one's own business is certainly one way of gaining recognition in society. However, this is not the case for small-scale miners. Their main interest is in putting food on the table for their families rather than gaining the prestige that establishing an entrepreneurial small-scale mining business could offer. A study assumes that the need for achievement is one of our basic needs and that women in particular are pulled into entrepreneurship by this need. Another pull factor towards entrepreneurship is a society which values personal achievements [35].

\section{Recognition}

Recognition refers to the social status derived from operating one's own business. He argue that push and pull factors of entrepreneurship are nothing more than motivation. Furthermore, motivation is usefully described by two theories: driven theory and incentive theory. Driven theory suggests that people are driven by internal stimuli such fear or hunger, whereas incentive theory describes people as being motivated by the desire for recognition or achievement. A study explored the career reason of nascent entrepreneurs. Their study tested two hypotheses ( $\mathrm{H} 1$ and $\mathrm{H} 2)$ :

- H1: Nascent entrepreneurs and a comparison group of non-entrepreneurs have similar scores on the six kinds of career reason (innovation, financial success, independence, recognition, roles, and self-realization)

- H2: Women (nascent entrepreneur and comparison group) rate the six kinds of career reason differently than men (nascent entrepreneurs and the comparison group).

To generate data for this study, they used a sample 558 participants made of up both nascent entrepreneurs and a comparison group. The results revealed that in the comparison group, there was a $68 \%$ variance. In other words, $68 \%$ saw entrepreneurship as a career choice while the rest saw it differently. A study investigated achievement, power and managerial motivation. He found that there was no significant difference between female or male managers in terms of their reasons for starting a business. He also confirmed that those that succeed in business do so because of their performance. He obtained different results in their research which investigated gender, entrepreneurial self-efficacy, and entrepreneurial career intentions. The study examined two sample groups; adolescents and Master of Business Administration (MBA) candidates. Their conclusion was; self-efficacy was a stronger motive for women than men. A study explored the motivations and scope and the nature of the expectation gaps experienced by mom-preneurs. This was a qualitative study, which used a series of structured interviews with a sample of 20 mom-preneurs. The analysis revealed that mompreneurs are pulled into entrepreneurship by internal elements, to a greater extent by rewards or wealth

Given that there is no evidence that small-scale mining entrepreneurs are driven by a desire for recognition or achievement, many would argue that small-scale mining entrepreneurs are driven into entrepreneurship by their circumstances. However, there is no empirical evidence for this. The abundant literature on push and pull 
elements is limited to small business start-ups. Little is said about the push and pulls elements from a small-scale mining perspective. Furthermore, these studies often focus on gender issues such as what drives males, as opposed to females, to start a business, rather than the characteristics of the person starting the business. It has been noted that some start a business for financial gain, while some do so for personal development. However, in the case of small scale mining, little is said about whether the entrepreneurs start a business with the goal of personal development [10].

\section{Personal development}

A study explored the reasons why owners or managers start their own businesses. To gather data, 405 participants were surveyed. They found that that the need for independence as part of personal development was the leading factor in motivating people to start their own businesses. A widely held view is that small-scale miners are not attracted into this kind of business because they are interested in personal development; the majority of them are not educated and do not plan to improve their personal competence [12]. Nor are they likely to be exercising their freedom and ability to pursue their own business ideas for financial gain. However, it is possible for culture to be one of the factors pulling people into entrepreneurship. For instance, some cultures encourage risk-taking and independent thinking. It seems too that small-scale entrepreneurs are pushed into entrepreneurship by poverty, culture and their values [1-3] On the other hand; Pegg [4] found that small scale mining entrepreneurs are pulled into entrepreneurship because of their need to diversify and to generate income. These opposing views highlight the need for research.

\section{Personal wealth}

A study examined self-employment entry into various fields, looking at a sample compromising of 24428 American individuals between the ages of 21 and 60 years old who were not entrepreneurs. This research revealed that people in this group who became entrepreneurs in the 1980 s already had a net worth in excess of $\$ 100000$ (approximately R1.19 million). A preliminary exploration of firms in gestation looked at who starts new firms. This study used an Automatic Interaction Detection (AID) which explored the uniqueness of the underlying factors behind start-ups. The outcome of this research revealed that $70 \%$ of business start-up in USA involved individuals between the ages of between 25 and 34 years old who were either managing a business or working part time or full time.

This is not always the case for small-scale miners, given the fact that the vast majority of them operate their mining activities in abandoned ghost towns that were once the site of large-scale mining. In addition, there were instances, where a select few small-scale miners had already established other businesses prior to operating a small-scale mining business. Starting and managing a business can result in financial gains. However, small-scale miners are confined to making very low profit margins. Evidently, small scale mining entrepreneurs do not start a small-scale mining enterprise to become wealthy, but rather to be able to provide food for their families. Small scale mining entrepreneurs are interested in making a basic livelihood, not in becoming rich.

If small-scale miners were able to determine their geological (mineral) reserves and expected turnover, they would attract investment from stakeholders interested in transforming the sector. However, at this point the biggest of the many challenges facing small-scale mining entrepreneurs is their lack of accurate geological information, relevant education and business expertise and experience. Furthermore, small scale miners are constrained not only red tape, but also their sense of why and how to start a business. This view is supported by Mkubukeli [10]. Nonetheless, If small-scale mining entrepreneurs were able to establish that they had legal claim to exploitable minerals worth in the region of R8 million, they could use this information to obtain financial security in the form of funds from financial institutions or relevant stakeholders (equity funders).

\section{Conclusion}

The aim of this paper was to explore the literature on whether small-scale miners are pushed and/or pulled into entrepreneurship. The review of the literature used the lens of the push and pulls factor theory, which deals with the factors that entice people to become entrepreneurs and factors that force people into entrepreneurship. It is not clear as to whether push factors or pull factors predominate or whether these key factors influence entrepreneurs equally. What emerged is that people are driven by different motives. These motives are influenced by factors such as age and gender. At present, the literature in this regard is very scantly, especially with regard to South African small-scale mining entrepreneurs. The following conceptual model is used as lenses into investigating these unknown elements in the case of small scale mining (Figure 2).

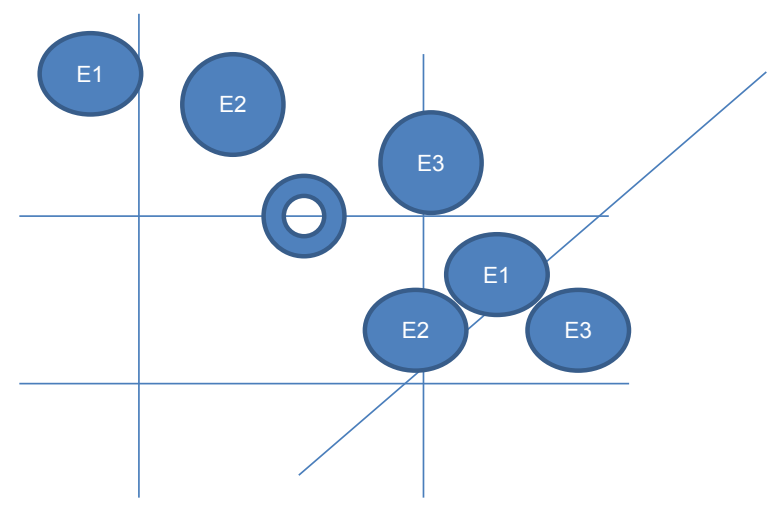

Figure 2: Push and/or pull elements into entrepreneurship.

The above figure consists of elements that pulls and push smallscale miners into entrepreneurship. The top right elements; Element 1 (E1) E2 and E3 are push elements and the bottom right elements; $\mathrm{E} 1, \mathrm{E} 2$ and E3 are pull elements. The middle element represents an equilibrium/combustion of both elements. What the elements are in SA remains unknown. Hence, further research is needed in order to determine these push and pull elements of entrepreneurship from a small-scale mining perspective.

\section{References}

1. Hilson G (2012) Corporate Social Responsibility in the Extractive Industries: Experiences from Developing Countries. Resources Policy 37: 131-137.

2. Hilson G (2009) Small-Scale Mining, Poverty and Economic Development in Sub-Saharan Africa: An Overview. Resources Policy 34: 1-5.

3. Hilson G (2008) A Load Too Heavy: Critical Reflections on the Child Labour Problem in Africa's Small-Scale Mining Sector. Child Youth Serv Rev 30: 12331245.

4. Pegg S (2006) Mining and Poverty Reduction: Transforming Rhetoric into Reality. J Clean Prod 14:376-387.

5. Nieman G, Nieuwenhuizen C (2009) Entrepreneurship: A South African Perspective. Pretoria: Van Schaik Publishers.

6. Evan JD, Dean AS (2002) Self-Employment as a Career Choice: Attitudes 
Citation: Mkubukeli Z, Cronje JC (2018) Pull and Push Elements of Entrepreneurship in South Africa: A Small-Scale Mining Perspective. J Entrepren Organiz Manag 7: 252. doi: 10.4172/2169-026X.1000252

Entrepreneurial Intentions, and Utility Maximization. Entrepreneurship Theory and Practice 26: 81-90

7. Shane S, Kolvereid L, Westhead P (1991) An Exploratory Examination of the Reasons Leading to New Firm Formation Across Country and Gender. Journal of Business Venturing 6: 431-446.

8. Barringer BR, Ireland RD (2010) Entrepreneurship: Successfully Launching New Ventures. Upper Saddle River, NJ: Prentice Hall.

9. Kirkwood J (2009) Motivational Factors in a Push-Pull Theory of Entrepreneurship. Gender in Management: An International Journal 24: 346-364.

10. Mkubukeli Z (2016) Challenges and Prospects of Small-Scale Mining Entrepreneurs in South Africa. Cape Peninsula University of Technology, Cape Town.

11. Straaten PV (2000) Mercury Contamination Associated With Small-Scale Gold Mining in Tanzania and Zimbabwe. Sci Total Environ 259: 105-113.

12. Hentschel T, Hruschka F, Priester M (2003) Artisanal and Small-Scale Mining: Challenges and Opportunities. International Institute for Environment and Development \& World Business Council for Sustainable Development.

13. Veiga MM, Maxson PA, Hylander LD (2006) Origin and Consumption of Mercury in Small-Scale Gold mining. J Clean Prod 14: 436-447.

14. Werthmann K (2009) Working in a Boom-Town: Female Perspective on GoldMining in Burkina Faso. Resour Policy 34: 18-23.

15. Sousa R, Veiga M, Van Zyl D, Telmer K, Spiegel S, et al. (2011) Policies and Regulations for Brazil's Artisanal Gold Mining Sector: Analysis and Recommendations. J Clean Prod 19:742-750.

16. Hilson G (2012) Family Hardship and Cultural Values: Child Labour in Malian Small-Scale Gold Mining Communities. World Development 40: 1663-1674.

17. Co MJ, Groenewald J, Mitchell B, Nayager T, Van Zyl J, et al. (2006) Entrepreneurship: Fresh Perspective. Cape Town: Pearson Prentice Hall Compact Oxford English Dictionary.

18. Hilson G, McQuicken J (2014) Four Decades of Support for Artisanal and Small-Scale Mining in Sub-Saharan Africa: A Critical Review. The Extractive Industries and Society 1: 104-118.

19. Venter R, Urban B, Rwigema H (2013) Entrepreneurship: Theory in Practice. Cape Town: Oxford University Press Southern Africa

20. Mutemeri N, Petersen FW (2002) Small-Scale Mining in South Africa: Past, Present and Future. Nat Resour Forum 26: 286-292.

21. Mutemeri N, Sellick N, Mtegha H (2010) What is the Status of Small-Scale Mining in South Africa? Discussion Document for the MQA SSM Colloquium, August 2010
22. Appiah $\mathrm{H}$ (1998) Organization of Small Scale Mining Activities in Ghana. Journal of the Southern African Institute of Mining and Metallurgy 98: 307-310.

23. Barreto ML (2012) Analysis of Formalization Approaches in the Artisanal and Small-Scale Gold Mining Sector Based on Experiences in Ecuador, Mongolia, Peru, Tanzania and Uganda, UNEP. Division of Technology, Industry and Economics (DTIE), Chemicals Branch, Geneva.

24. De Lacerda L (2003) Updating Global Hg Emissions From Small-Scale Gold Mining and Assessing Its Environmental Impacts. Environ Geol 43: 308-314.

25. De Lacerda LD, PfeifferWC, OttAT, da SilveiraEG (1989)Mercury Contamination in the Madeira River, Amazon-Hg Inputs to the Environment. Biotropica 21: 91-93.

26. Dreschler B (2001) Small-Scale Mining and Sustainable Development within the SADC Region. International Institute for Environment and Development \& World Business Council for Sustainable Development.

27. Hilson G, Murck B (2000) Sustainable Development in the Mining Industry: Clarifying the Corporate Perspective. Resources Policy 26:227-238.

28. Hinton J (2012) Analysis of Formalization Approaches in the Artisanal and Small-Scale Gold Mining Sector Based on Experiences in Ecuador, Mongolia, Peru, Tanzania and Uganda, UNEP, Division of Technology, Industry and Economics (DTIE), Chemicals Branch, Geneva.

29. Nieuwenhuizen C (2015) Entrepreneurship: In Lamb, Principals of Business Management. Cape Town: Oxford University of Press Southern Africa (Pty) Ltd.

30. Pfeiffer WC, De Lacerda LD (1988) Mercury Inputs into the Amazon Region, Brazil. Environ Technol Lett 9: 325-330.

31. Phiri SN, Ncube A, Mucherera L, Ncube K (2011) Artisanal small-scale mining Potential ecological disaster in Mzingwane District, Zimbabwe. Jamba: Journal of Disaster Risk Studies 7: 158.

32. Shen L, Gunson AJ (2006) The Role of Artisanal and Small-Scale Mining in China's Economy. J Clean Prod 14: 427-435.

33. Shenton AK (2004) Strategies for Ensuring Trust Worthiness in Qualitative Research Projects. Education for Information 22: 63-75.

34. Singo P (2012) Analysis of Formalization Approaches in the Artisanal and Small-Scale Gold Mining Sector Based on Experiences in Ecuador, Mongolia, Peru, Tanzania and Uganda. UNEP, Division of Technology, Industry and Economics (DTIE), Chemicals Branch, Geneva.

35. Taylor H, Appleton JD, Lister R, Smith B, Chitamweba D, et al. (2005) Environmental Assessment of Mercury Contamination from the Rwamagasa Artisanal Gold Mining Centre, Geita District Tanzania. Sci Total Environ 343 $111-133$. 